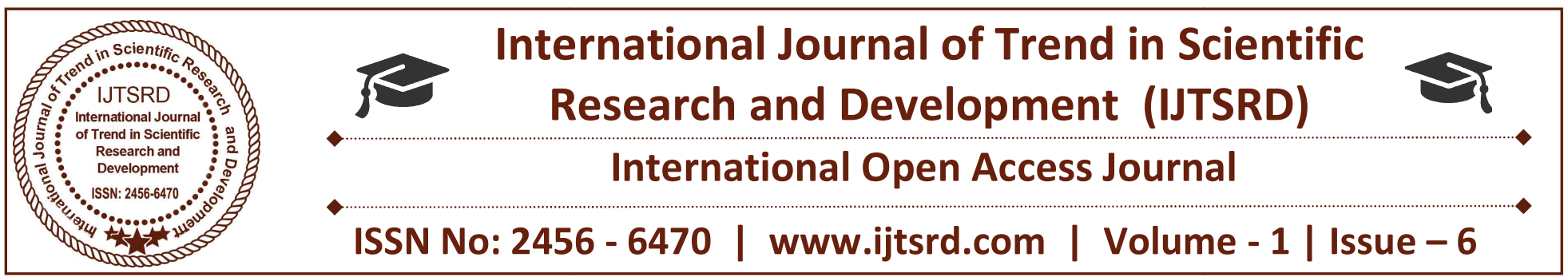

\title{
Understanding Comparative Literature
}

\author{
Santosh Kumar Nayak \\ Assistant Professor in Odia (OES-I) \\ Department of Higher Education, Odisha \\ Trainee at Fakir Mohan University, Vyasa Vihar, Odisha
}

\begin{abstract}
This paper tries to unveil the secrets of comparative literature and to simplify the codes of conduct in it. The tools and different aspects of CL are tried to be discovered here. The modus operandi of CL and the role of language and of course the function of translation is mentioned here. Here, attempts have been taken to enlighten on the Dhvani Theory with respect to the Reader-Response Theory of the West. Attempts have also been made to prove that CL may also be taken with a special reference to the reader response theory which will give a better and new result. Julia Kristeva's theory has also been taken into account with respect to comparative study of the texts.
\end{abstract}

Keywords: Comparative Literature, Visva Sahitya, Welt literature, Rasa, Dhvani, Deconstruction

\section{Introduction}

All these branches of literature are because of the world we live in. We are talking about subsections and subunits of a branch or a discipline because of the pattern we live in. We can simply name this a 'nuclear pattern'. That is diversity from and within unity. For example, literature is one but we have several disciplines within it. Again, every discipline is special and unique to each other. Individually they have different the modus operandi, though having a common goal. In this complexity, we find a discipline called Comparative Literature (CL).

\section{Comparative Literature: Its Meaning and Scopes}

Simply, the term 'Comparative Literature' explains itself about its modus operandi, i.e. it says how comparison is the primary work in it in order to obtain certain elements from the literatures involved. It can be told that CL is nothing but a kind of criticism. But could it simply be said or even named 'one dimensional criticism'? No, it may be a type of criticism but criticism exactly as its goals vary from critical analyses. Some of the critics say that it is quite difficult to define CL for it evolves not one but two or even more than two literatures in comparison synchronously.

\section{"It becomes still more difficult task when the comparatist has to take into consideration the multi-dimensional aspects of comparative literature such as-linguistic, cultural, religious, economic, social and historical factors of different societies." $"[1]$}

In order to unveil the meaning of the term 'comparative literature' we must have to analyze its nomenclature. Again, etymologically the term ' comparative literature' denotes any literary work or works when compared with any other literary work or works as it has been derived from the French words 'comparatif' and 'litterature' or the Latin terms 'comparativus' and respectively which means 'proceeding' or 'estimating' and 'learning'. The original words of 'comparative' denote a kind of study, estimation or a kind of proceeding whereas the original words of 'literature' denote a kind of learning. It is "the collective body of literary productions, embracing the entire results of knowledge and fancy preserved in writing [...]", says Webster. In this way we can better identify CL as the serious and objective study of inter-relationship 
between any two or more significant literary works or literatures with respect to the backgrounds of the said works. It may be clarified that the background, here, refers to the socio-cultural, political, economical, anthropological, psychological and other things. During comparative study and analysis, for a better result and qualitative output, one must take the sources, themes, myths, forms, artistic strategies, social and religious movements and trends into account. The approach of the comparatist must be very alert and descent from each and every angle. A comparatist with his critical introspections and investigations needs to find out the similarities and dissimilarities among various works that he has undertaken (his universe) for the purpose of his/her study. So far about the context of justification to the findings and unbiased attitude towards the methods and modus operandi, we can only say this much and that it is the heart soul of the total process from alpha to omega. Hence, it is also that much momentous in the whole comparative study. We must take proper care of this fact during the entire study that proper justification has been given to the facts and the found phenomena. Then only one can reach the ultimate truth and can yield a better result thereby. But it should be crystal clear from this study that there is no ultimatum or the eventual point of this kind of research. A comparatist is like a father of both/all the texts he has undertaken. That is he must not be biased at all by his own mother tongue, literature or culture, religion etcetera. He must hold a huge and a greater vision in him. Like a father likes and loves to his children, a comparatist must hold that much love and affection in his heart to all the selected texts (works), like Brahmaa loves his universe, a researcher or a comparatist, especially, must love at that intensity to his universe. Like research, in CL or in comparative study it is the ultimate ethics of the comparatist. To be crystal clear and thoroughly vivid regarding this matter, it is only and only his earnest and sincere measure which will bring forth the raw and unclothed truth as well as the pure natural results what so ever we may say. This is exactly what we call the main objective of comparative study.

\section{Understanding $\mathbf{C L}$}

Comparative Literature is of course a comprehensive term and often a greater term with wider range and domain than comparative study or analysis etcetera. One of the scholars speaks regarding the scope, function, objectives, and vastness and of course, the cream context of CL that:

"Its scope encompasses the totality of human experiences into its embrace, and thus all internal human relationships among the various parts of the world are realized, through the critical approach to literatures under comparative study. It helps to vanish narrow national and international boundaries, and in place of that universality of human relationships emerges out. Thus the term comparative literature includes comparative study of regional literatures, national literatures, and international literatures. However, there are many over-lapping terms in this concern such as - Universal literature, General literature, International literature and World literature. Repeatedly, we can mention here that comparative literature includes experiences of human life and behaviour as a whole. In the conception of world literature the works of Homer, Dante, Shakespeare, Milton, Goethe, Emerson, Thoreau, Valmiki, Vyas should be taken as one for comparison.",[2]

Here, we must not fail to mention the significance and demand of the term World Literature (WL) amongst the critics of the whole world. Yes, there is not only a little beat difference between CL and WL but also we must say that there is a greater significance in using the term world literature. Therefore may be, with a keen vision of course, the researcher-cum critic, to this, adds the following few lines with exemplification as given below:

"Virgil's Aeneid, Homer's Iliad, Milton's Paradise Lost, Indian Epics-the Ramayana and the Mahabharata can be studied in comparison as world literature."[3]

$\mathrm{CL}$ is in fact a serious need of the hour. We must take the psychological phenomena into our account while discussing about the CL and comparative study of the world classics. Psychologically, the human nature is almost same in every part, every sphere and in almost all over the world. That is why; human expressions in all literary works are bound to have deep-rooted similarities between them. Hence, there lie not only similarities but also intense affinities between the world classics to which we can say masterpieces of different time and places and even 
of different nations. Literature is basically an expression of own intimate and chesty observations of the human behavior with own approach and introspection. Eliot's The Waste Land and Guruprasad's Kaalapurusha, Paraja, the great work of Indian author Gopinath Mohanty and Things Fall Apart, the ground breaking novel of Nigerian novelist Chinua Achebe or we can name different classics of different times from ancient period to the medieval period etcetera who are not only branded classics but also have immense similarities among them. Human nature, no doubt, is very complicated as $\mathrm{s} /$ he has got the highest cerebral development in the trend of time and evolution. And it is quite obvious that the said complexity remains both in the 'observed psychology' as well as in 'observer's psychology'. Both in character and writer the complexity remains as such just as the light remains above the experiment table from the light source (incident light) as well as from the reflector (reflected light). In Toto, this complexity as a whole in different kinds of literary works makes a complex phenomenon with which the CL deals. In this way, the comparative study becomes more and more complex and interesting at the same time.

Comparative literature is quite different and special than this comparative study. Because CL has its specific objectives and modus operandi that the comparative study may follow or may not. In this way we can say that this comparative study is a super set of the CL and at the same time CL is quite special though is a subset of the other. All kind of comparison is allowed in comparative study but in CL the observations should be very specific and objective oriented. The anthropological and cultural shadow is quite permanent as a compulsory department in $\mathrm{CL}$ while it is clearly optional and of course not mandatory in case of the other. Some say that:

"[...] the comparative study is not different from a critical approach of a particular literature except the fact that here we deal with two or more than two literatures side by side. In this way, the subject matter becomes vaster and perspective wider. Boundaries of comparative literature have to be extended to encompass the entirety of human life and experiences in one's embrace."[4]

This kind of statement is also true in case of CL where it is more flexible. Though here, the author has pointed out that the comparative study is just like the other critical studies with multiple texts/ works, still it is only said in order to broaden the domain and range of the perspectives of the traditional modus operandi of CL. Now-a-days, a comparative study may be done between a novel and a travelogue or between a story and a novel or between unlike forms of literature. Now, the national boundary has been squeezed to the local boundary for a comparative study under the umbrella of CL. Even, the comparative studies have been made between the texts in a particular language of the same and of course of different time period. B.K. Das has worked good enough, though little, in this field. The specialty of Dr. Das is he illustrates very well and gives the most simplified and digested form of a complex theory. He has also given a definition of CL with his lively and catchy words. The said definition may be quoted right here for the purpose of clarity in this discussion. He says in his book Comparative Literature:

"The simple way to define comparative literature is to say that it is a comparison between the two literatures. Comparative literature analyses the similarities and dissimilarities and parallels between two literatures. It further studies themes, modes, conventions and use of folk tales, myths in two different literatures or even more." $(01)$

What Tagore told is very important to CL. Again, it was a challenge for CL at that time just to come out from the narrowness. The concept of Regional Literature (RL) was there and will be forever. But we need to enhance the wave length and range of our vision. We should be global instead of being local. We should be outward instead of being only inward. But it is very much clear that one must look inside but never should be self-centric. One must be retrospective, prospective, and introspective at the same time while looking into the works in the CL forum. R.N. Tagore, with that much broader sense had a thought regarding this to which we call Visva Sahitya. During a comparative study, he remarked, one must have the capacity to through his own vision as far as he can. It is, according to him, good for the health and wealth of the said comparative study which further enriches the domain of CL. Broadening the scope of CL he remarks: 
"From narrow provincialism we must free ourselves, we must strive to see the works of each author as a whole, that whole as a part of man's universal creativity, and that universal spirit in its manifestation through world literature" (Quoted in Buddhadeva Bose, "Comparative Literature in India, "Contribution to Comparative Literature ; Germany and India, Calcutta, 1973). [5]

All those concepts of World Literature, Universal literature or you say the welt literature, each one of these has the only goal and that is to be broad minded by accepting all the literary works of the different sects of the world own. Historically, if we peep back into the past, we will find CL has been a significant consequence of the reaction against the narrow nationalism of the nineteenth century scholarship in England.

"Though it was an occasional tradition, the comparative study of literary works was in vogue, right from the beginning of the Christian era. Romans were the pioneers in the field of comparative study. They out did the Greeks in the development of comparative study. The Romans worked out the tradition of comparing the works of great orators and poets of Greek and Roman and found out many similarities among their studies of literary works. No doubt, Quintillion was the pioneer in this concern, but Longinus endeavoured to set the comparative study in systematized discipline. If he had preceded Quintillion he would have been the pioneer in this field. He brought forth the names of Homer and Plato etc." [6]

We have also seen this rich tradition in the ancient Sanskrit literature and its critical and analytical genre. In ancient Indian literature, especially in Sanskrit, we notice various comparative approaches, which are quite qualitative too. Around $600 \mathrm{AD}$ the critics and the commentators like Acharya Kuntaka and Acharya Abhinabagupta as well as Acharya Aanandavardhana have given their marvelous innings in this field. The approaches, they have made over their study, are really remarkable and praiseworthy. It is transparent and vivid enough from the commentaries made especially on Kalidasa's Meghduta and Abhijnanasakutala. The critics like Kuntaka and Abhinavagupta have given the best and beautiful innings at the very first stage with a crystal- clear qualitative approach which almost paved the way for the modern comparators. But it could not be told strongly that these criticisms were the milestones of CL. But, of course, it will be a great mistake by us if we won't say about Bharata Muni's Natyasastra and its socio-cultural approach right here. The attempts made by Bharata Muni are purely research based and anthropo-geographical in nature.

Comparative Literature, after getting a special recognition, has started its smooth and rich innings in the trend of time. It has been receiving a great order and degree of honour from the critics and the scholars of throughout the world. The dimension and the domain of CL have been increased in the last few days. Many of the scholars are also doing research exclusively on the history and the trend of CL. R.S. Pathak, giving his peer view regarding the development and enrichment as well as the history of this new discipline says:

"Mathew Aronold made meaningful efforts in English world and emphasized strongly the significance of the comparative approach to literary works. He wrote in a letter in 1848, "Every critic should try and possess one great literature at least besides his own and more the unlike his own, the better."[7]

In this way, he pioneered the Comparative Criticism (CC) in England and propounded certain code of conducts regarding this. He suggested for the new disciple and inspired the critics to emphasize on it in order to enhance the quality of criticism. With certain points he argued and fact fully he was fair too in his points in order to establish his argument in favour of $\mathrm{CL}$ and its objectives as well as modus operandi. This was really a new approach to the critics of that time. But the original objectives of criticism meet here with the proper operation with the anchors of comparative study. He has directly and of course indirectly motivated to other critics to work seriously on this fresh discipline in order to do something new and better.

For comparative study there has already been prescription for the new critics, that is to whom or between which types of texts the study may be done. A comparatist must choose such works which has a greater impact, cosmopolitan value, having national and international importance and of course much more significance in the society. This kind of study and examination aim not only 
to build the cultural relationships between the different geographical sects but also try to make a milestone in world criticism which will ever be exemplary.

"It is hereby suggested that the comparatist should undertake the master pieces of creative writers, whose works have cosmopolitan status in literary fields. That is why, Ezra Pound and T. S. Eliot called for a criticism of poetry on parameters of universal worldpoetry, or the works of maximum excellence. This type of approach will direct comparative study of literature towards international level." $"[8]$

\section{Tools and Aspects of $\mathbf{C L}$}

There are different tools and aspects of CL which are used during comparison. Comparison is not made simply one by one in CL. The comparatist has to first of all find out or dig out the things in which the text is embedded and from which the germination of the literature occurred. With them in his/her hands $\mathrm{s} / \mathrm{he}$ has to proceed. Then only the comparison will be more effective and objective. In his unique article, "Comparative Literature and Aesthetics: the search for a significant order" R.S. Pathak has indicated certain well-known aspects of traditional comparative studies. The aspects could be discussed below shortly one by one:

Folklore: Folklore is a very big term which may have several meanings. But let me clarify that the term 'folklore' here refers to a cultural background which of course dictates and commands in the primary literary work of an author. It is the cultural identity and literally nothing more. This is the sole and important most factor which starts inhibiting the author to think in a proper way as per its own cultural dictation. We may call it cultural currency or socio-cultural mitochondria which provides scopes and energy to think at first. Folklore offers the frame and twist in the text both thematically and stylistically. It, of course, opens another class and genre to think and rethink for the further thematic and pragmatic studies. This unfurls the tremendous vistas of CL or the comparative study day by day.

Influence: Right here, we can think of the words of T.S. Eliot, the great critic and poet, the darling of New Criticism. He once said that no one poet, no one writer in this world is completely free from the impacts of his/her ancestor. It is really a matter of fact. Nobody can be free absolutely from his past and ancestors. In Odia literature we see Upendra Bhanja has been moved by the Sanskrrit poets as well as some of the early poets of Reeti Age (The Age of Mughal/ Ornamentation) and more particularly of the early phase of the age like Shishu Shankar Das, Dhanajay Bhanja, his grandfather and many other Odia poets. Eliot himself has committed that he has been deeply moved by his literary ancestors like Dante, Milton, Cornard, Frazer and some myths, folktales, legends and other socio-cultural cum ancestral products. Radhanath Ray has admitted that he had followed his literary ancestors. And some other critics accept him as the last poet of the age of Ornamentation. He has adopted the ornamentation techniques and other formalities even of his previous literary age. Likewise, Guruprasad Mohanty has been affected by several Indian and Non- Indian authors like Jagannath Das, Sarala Das, Sachhidananda Routray and T.S. Eliot, Pound, Malarme and some other persons by virtue of their notable works. Similarly, Mazzini once said that a developed, cultivated literature, nurtured by itself, without influence from a foreign literature, is something unthinkable. He directly denied that this kind of literature can hardly be created. Many a number of big writers have been affected by this critical ailment. Centuries before him, in Sanskrit,

"[...] the Indian Poetician Rajasekhara had maintained that it is not that poets are not thieves. Writers have borrowed and even plagiarized occasionally in all ages, and some points of affinity between masterpieces of different literary traditions can be established on comparison." [9]

Now, we have a couple of concepts, i.e. National Literature (NL) and Regional Literature (RL) clearly at our hands. In the support of above mentioned facts and points we can give details from Indian National and Regional Literatures. In Indian context, we may say right from the Aryans to the British Advent to this main land of India. Because the people of Dravidian and Austric race are the original inhabitants of this mainland. The Aryans were found powerful culturally and of course politically, due to which they not only suppressed the sociopolitical voice and stream of the native people but also set up their own cultural identity in such a way, and in such a strength they had put the foundation of their linguacultural pillar that we are now really confused about 
the origins of Modern Indian Languages, whether they have been evolved from Sanskrit or other Dravidian and Austric languages. Even Sanskrit was the lingua franca for a long period, especially of the northern belt of India. It is purely due to the Aryans. Similarly, we can cite the examples of the Mughal empire. The Muslim culture, language (Persian), behavior, other socio-political, socio-cultural, linguistic approaches along with their traditions, therefore have some impacts on the modern day languages, culture, literature and other social documents of India.

Now, we can talk a little about the language Sanskrit. It is believed to be a pious language which is spoken by the Hindu Gods. Hence, the Purans and the Vedas and Upanishads are written in this language. We are emotionally as well as psychologically connected to these things and hence, the rituals and cultural matrix of these things are also found in our vein and brain. Ergo, while writing a piece of literature in any form, it is quite obvious that the impacts of these things will be reflected upon. Political power and empires has a great impact of course on the literature and other socio-cultural affairs. Therefore, even in the folk items (folk literature), i.e. in folk song, folk tales, folk drama, proverbs etcetera, for example in Odia folk literature, we find the micro elements of Mughal culture and tradition since Odisha has been ruled over by the Mughals for a long period in the past.

"Sanskrit being the language of ancient Hindu scriptures had its influence on Indian literatures especially on Northern Indian languages leaving aside Urdu, which is a language of the recent origin. Undoubtedly, it had not influenced much on Southern Indian literatures. Still being the language of Hindu religion and culture, it did play a significant role in the process of development of Southern languages." [10]

Sanskrit entered into the vein in a different manner. The impact of the Sanskrit culture from different books and Purans came directly through the religious matrix. Similarly, the case of Mughal impact can be told. The case of this Perso-Arabian impact is something different from that of Sanskrit. Here, the political infrastructure is main thing and rests are minor factors to affect. As Persian was the language of the court of the Mughal kings and was the royal language of the period, with the advent of Muslim rule in India, Persian, even though a foreign language, highly affected the Indian literature as well as Indian culture, art, architecture, music, dance etc in the very same way. A hybrid culture came into existence to which we call here in post-colonial diction a Glocal Culture. The Kathak dance, the form of Ramlila was enjoyed at the Mughal Court at that time. Muslim monuments acquired Hindu temple motifs. Many Muslim kings and emperors attacked the major Hindu temples and tried to devastate, disturb and perish the socio-religious, cultural and other ritual documents, sanctity and beauty. The attack of Kalapahara to the Jagannath temple of Puri, Odisha is the perfect instance in this regard. As a matter of fact, there in that period Urdu, a dialect, originated from the barracks, and became a highly sophisticated and sweet language of literary expressions having no religious text at its support. This rose only due to the political influence and Mughal dynasty in India.

Yes, it is equally true that the Aryans and the Muslims have been influenced by the Indian cultures, traditions language and literature and some other approaches as well. The reciprocal impact on the British people was not possible due to certain facts. Some of the British people came to India and had direct interaction with the Indian people, culture, tradition, belief, customs and other aspects where as some other regulated the reign and all the phenomena from London. At the same time, all Indian were involved in the process of change here. Critically, regarding this, a scholar says:

"It is a fact that Aryans and Muslims settled in India and made India their home. They influenced Indian culture and also adopted the Indian ways of life. The English ruled Indian from abroad and did not follow the main stream of Indian culture. Influence of the west could be seen in all aspects of Indian life, Indian culture, philosophy, politics, educational policies even medical sciences. English schools were opened and they taught English to the Indian people for communication purposes and they also propagated their religion on Indian soil. On the other side when Raja Ram Mohan Roy visited Europe in 1830, it was just the first attempt of an Indian scholar to explore Europe and the process of give and take continued."[11] 
In the post-colonial context, we see how a hybrid product is coming out of this. A group of people are doing the same thing as the British people though they are Indian by blood and birth. Not only politically and diplomatically but also socially and culturally they are doing the functions of the English people. These cultural currencies transformed into the Indian people's mind and heart by the long interaction with the British rulers. According to Homi K. Bhaba and Edward Said, after going through the theories propounded by them, we will be quite clear about the matter. Unlike the British people, the American came to India with different kind of quests like spiritualism, cultural and philosophical exchange etcetera. Along with these quests the American scholars show their keen interest in knowing the map of Indian social life more and more.

We can know how 'influence', the important most aspect of traditional CL, according to Pathak, works in what height in case of the American. They, initially came to India for the sake of trade and commerce only but with the trend of time they started taking interest in socio-cultural exchange. Further, they became more close to the Indian spirit and soul of society, which resulted later into a keen interest in the linguistic, ethnographic, racial, behavioural, literary and philosophical heritage of India. It is very interesting and also a matter of happiness that when the entire western world was indulged in material prosperity, only the American scholars looked upon the east as their only hope for their spiritual rejuvenation. Because, from the ancient literature of India like the Vedas and the Upanishads they have a constant hope to get the way of real happiness and peace in life. We can say in other words that they were prospecting for the path of salvation. The Transcendentalists like Emerson, Alcott and Thoreau thoroughly studied the Hindu myths and ancient Hindu philosophies and found a close kinship among their own thoughts and philosophies with it. A number of Indian classics were translated then into English by the e minent Scholars like Raja Ram Mohan Roy, Sir William Jones and the Charles Wilkins etcetera. It is a matter of pleasure that the American Readers responded to these translations enthusiastically.

Even Mahatma Gandhi, at that time, investigated the American philosophy with reference to their philosophers and was highly impressed by the philosophical views of Thoreau. He found that all the people of the world are one and they are the offspring of the mankind but not of the East or the West. He then found many similarities between their thoughts during his study. We can look into this matter from other side and that is, from the Comparative Literature's point of view.

Genre: Genre implies Kind, genus, class or a form with special style in literature. It also means a special kind of text with certain socio-political background. It has been an important element of CL curriculum. Ferdinand Bruntiere was the first person showing deep interest in the evolution of genre. According to him every literary type has a birth, development and an interesting rise and fall with its wax and wane. During the study of texts or works we need to study their genres. This will help us finding the route of the literature as well as its social significance. We can map it well from the history to the present day. Again, before comparing or before going for a comparative study with regard to the ideologies of CL we must have to know their genre well. This will ensure the scholar to reach easily at the findings and will help to have clear objective(s) much before the study, which will streamline the entire study. For example, before comparing Chinua Achebe and Gopinath Mohanty we have to find out their genre with proper care. Again, after studying the details of Achebe's works we will be much clear about the genre of 'Things Fall Apart' and similarly in the case of Mohanty's ground breaking work 'Paraja'. Both are the significant works of Nigerian Igbo tribe and Paraja tribes of Odisha respectively.

Theme: The English word theme has its Latin origin from the term 'thema' which of course means the subject matter of a text. We can simply say that 'the motif of a text'. The themes of the works must be another priority of a scholar while comparing them with regard to CL. The themes hold the psychology, cultural factors and even the social and political currencies in them. Upon these possibilities we look into the themes of the specific works. Comparison between the themes of the selected works is enough for the culture estimation and mapping the sociocultural, political and anthropological background. The psychological affairs (both of the author and the people/ characters involved in that) could also be trapped and followed by virtue of these thematic aspects. For example we can take the instance of 'Things Fall Apart' and 'Paraja'. How the Igbo tribe is fighting for the preservation and rescue of its own culture and social heritage, we can see from this novel. Similarly, the Paraja tribe has been crushed by 
the upper class social people as well as some Christian 'Dama'. There in the novel 'Things Fall Apart' the process of post-colonialism is continuing and hence there is a protest and loss is seen. But in 'Paraja' the case is different. Because, in this novel, the entire plot has been affected by a special group of people called 'the Post-colonial hybrid products' like Rama Bisoi, the cruel and cunning money lender, the Jungle Jamaan (The Forest guard), Kaau Paraja, an inhabitant of Sarsupadar village and some other people. They are functioning as the colonizers and continuing the process of socio-economic exploitation. But in case of Nigerian plot, there, has been a decline of culture and social heritage of the tribe. The Christians have captured the place along with their culture and social customs and in this way they are devastating the same too. For this only, the title of the novel has been given like this, though he has borrowed it from the internationally acclaimed Nobel prize awarded poet W.B. Yeats. Similarly we can take the example of the two master pieces of the twentieth century: 'The Waste Land' and 'Kaalapurusha'. Here, from the very first lines of both the poems we not only encounter the poetic currency of style but also we get the geo-cultural and geo-political specialty. In this way, the study and investigation with reference to the themes of the selected works holds the possibilities to find out the socio-cultural and psychological factors of the associated society. ${ }^{[12]}$ Because society is such a pattern which is governed by the web of sociocultural interrelationship and based upon the symbiotic relationship in between.

Except these things, a comparatist must have to look into the works with ample historical perspectives. However, "the comparative method should deal with the piece of literature historically", says Hudson. Many of the critics believe in this fact that CL will give its best service when it will deal with the literatures historically and this will have a great service to the society. After his return to Russia in 1870, Alexander Veselovsky brought out a series of documents on his serious observations and experimental studies on the migration of themes, ranging all over the western and eastern hemispheres of world. Similarly, we can cite the example of Richard Price, who in his preface to the new edition of Warton's History of English Poetry(1824) regarded literature as a huge treasure trove of themes which spread, multiply and migrate. French scholars have taken several significant efforts in order to collect evidences about literary relations and migrations of themes and motives all over the world.

CL has some other significant aspects which could also be described shortly right here below:

Criticism: If we look into the matter, we will be sure enough that comparative literature (CL) is nothing but a kind of criticism only. Says Dr. Prafulla Kumar Pati:

"All men are interested in literature, for it is concerned with human beings. So, when a student comes across a work of literature, he naturally tries to interpret it. In the absence of any guidance, he will naturally interpret it in the light of his own ideas, and his criticism, therefore, will be subjective.'(xxii)

He adds, here, the speculative comments of Austin Warren to his comment in his 'Introduction' and says:

“Austin Warren (1899-1986) has rightly observed; "Subjective theories are pernicious; only objective theories, based on objective criteria, make criticism value-based". [...] according to T.S. Eliot (1888- 1965), the two goals of criticism are, "the elucidation of works of art and the correction of tastes". By following the models, offered by these critics, a student can surely improve his capacity for properly elucidating works of art, and his taste will get corrected."(xxii)

Criticism is of course a significant factor in the field of CL. Criticism of a literary work does not mean only to find out its weaknesses or defects or flaws only. Critics should highly eulogize the good qualities, the strengths or the fortes of the work 'if discovered'. To Renan-The method of comparison is a "grand instrument of criticism" ( $L$ ' Avenir de la science) (Paris, 1890 p.269). [13] CL belongs to the genus of Criticism though it has some special species. Here, it should be clear that, in comparative criticism, we have not only to find the negative aspects, the weakness and flaws of the selected works but also we should have to mention the discovered positive qualities and the strengths of the texts at the same time. This is, in fact, the forum of CL. M.H. Abrams defines criticism very precisely. His point of view is important here. He says:

"Criticism, or more specifically literary criticism, is the overall term for studies 
concerned with defining, classifying, analysing, interpreting and evaluating works of literature." (49-50)

The last point, he said, is very important to our concern, i.e. to CL. In CL, we have to evaluate the texts well. Evaluating means, analysis and one kind of discovery of all the aspects of the works; good and bad both. From each and every angle of the works, a critic must look. Further, there are different types criticisms like 'Theoretical Criticism, Practical Or Applied Criticism, Impressionistic Criticism, Judicial Criticism, Mimetic Criticism, Pragmatic Criticism, Expressive Criticism, Objective Criticism, ${ }^{[14]}$ Cultural Criticism, Psychoanalytic Criticism, New Criticism, Myth Criticism, Marxist Criticism, Phenomenological Criticism, Russian Criticism, Humanistic Criticism, Moralistic Criticism, 'Symbolistic Criticism', [15], Latin Criticism of Different Times, Italian Criticism, Greek Criticism of different times etcetera. In case of CL, we need to interpret the text with regard to the culture involved. After 1957-58, in literary criticism, the emphasis on culture was given top priority. To be more particular, the discussion on culture studies was accelerated soon after the publication of Richard Hoggart's 'Uses of Literacy' in 1957 and Raymond Williams' 'Culture and Society' in 1958. Similarly, just after the establishment of Brimingham Centre for Cultural Studies culture studies was popularized in England and in other English speaking parts of the world. Says B.K. Das in his book 'Twentieth Century Literary Criticism' in this regard:

"Cultural Criticism, the upshot of Cultural Studies is something used interchangeably with the latter. Since Culture is now considered as a source of art and literature, Cultural Criticism has gained ground. And therefore, Raymond Williams' term, 'Cultural Materialism', Stephen Greenblatt's term 'Cultural Poetics' and Mikhail Bakhtin's term, 'Cultural Prosaics' have become significant in the field of Cultural Criticism.” (131)

Marx's base model of society or the superstructure model of society worked as a catalyst for the popularization of culture studies. We can go through the analysis of superstructure of society which of course goes reverse the economic growth. "Cultural critics now consider culture as a source and not just a representation of art and literature."(132), says B.K. Das in his famous book Twentieth Century Literary
Criticism. A word comes from culture of a society whereas literature exists in language. That implies the literature exists in the particular culture. Hence, the cultural critics are giving much importance to culture in order to unveil the reality and possibilities inside the text of the literature. We must encounter the words of Ross Murfin and Supriya M. Ray in this regard:

"Cultural critics examine how literature emerges from, influences and competes with other forms of discourse (such as religion, science or advertising) within a given culture. They analyze the social contexts in which a given text was written, and under what conditions it was -and is- produced, disseminated and read. Like practitioners of cultural studies, they oppose the view that culture refers exclusively to high culture, culture with a capital $\mathrm{C}$, seeking to make the term refer to popular, folk, urban and mass (mass-produced,-disseminated,-mediated, andconsumed) culture, as well as to that culture we associate with the so called "great literature". In other words, cultural critics argue that what we refer to as a culture is in fact a set of interactive cultures, alive and changing, rather than static or monolithic. They favour analyzing literary works not as aesthetic objects complete in themselves but as works to be seen in terms of their relationships to other works, to economic conditions, or to broad social discourse discourses(about child birth, women's education, rural decay, etc.). Cultural critics have emphasized what de Certeau, a French theorist has called "the practice of everyday life," approaching literature more as an anthropologist than as a traditional 'elitist' literary critic." (66)

It is equally true that the cultural criticism is very much closer to the post-colonial criticism. If we exclude culture from literature it will be just like the cell but the sap or a tree but the wood. By the way, the term 'culture' is really illusive as well as a set of practices. W.L. Guerin and four other critics have tried hard to find the areas of cultural studies. Those points may be quoted right here below:

"Arising amidst the turmoils of the 1960s cultural studies is composed of elements of Marxism, new historicism, feminism, gender 
studies, anthropology, studies of race and ethnicity, film theory, sociology, urban studies, public policy studies, popular culture studies and postcolonial studies: those fields that focus on social and cultural forces that either create community or cause division and alienation."(240)

CL has different facets to express itself. It goes beyond the power structure of society like culture studies being parallel to it in a number of respects. It never accepts the autonomy or the self-controlled model of literature. Says B.K. Das in his book Twentieth century literary criticism:

"Culture studies go beyond the frontiers of a particular discipline such literary criticism proper or social sciences. It is interdisciplinary in approach and therefore, it encourages intertextuality." (133)

Comparative criticism is nothing but the agent to approve this intertextuality, interdisciplinary aspects of literature. By the way, this way the range and domain of CL has been changed and widened. And all these occur in the super domain of criticism.

Translation: Translation is a vehicle which moves the message of CL faster and makes CL easy to happen. Translation is boon for CL. A good translation will not only translate or carry forward the theme or the thought of a text but also it carries the heart of a nation, a race and a person forward. It has the ability to bring forward the dummy soul of a text. In comparative studies, translation has a very significant place. A primary introduction is received after reading a translation of a particular text. All that is because, a language or a single word has its own history as well as a cultural background behind its back. In translation those things lost easily. Translated pieces sometime help the scholar to know the fact or the thematic goodness, strength or weakness of the text and even sometimes it helps to know the culture behind it without knowing the language. But the translation should be chesty as much as possible and should be closer to the original work.

"Translation can be used as a tool for comparative study. English translation of European classics will help Indian students to make their comparisons with Indian literatures. Similarly, Indian classics in
English translation will be helpful for European students in comparative study with their own literatures. Thus translation helps the students of comparative literature to develop an international approach in different spheres such as literary, economic, social, philosophical, religious, cultural, historical and artistic values." $[16]$

It is true and well known that translation is important to comparative studies of world literatures but it is equally true for the regional literatures. But we must mean translation with an adjective 'successful'. That is, without a successful translation the comparative approach will miscarry the whole motion. Therefore, the critic or the comparatist must be a versatile and at least comfortable in both the languages involved in the comparative study. That means also that $\mathrm{s} / \mathrm{he}$ must be a good translator. At least during his/her reading of the text or during the comparison $\mathrm{s} /$ he must have to translate the same into his/her own mother tongue or into the second language in his mind.

A piece of translation of the original literary work cannot render the original taste. Yet it can be better than the original work. But this case is completely rare.

According to Henry Gifford:

"A work translated can never be more than an oil painting reproduced in black and white. A translation, however impressive, cannot truly coexist with the original. The original works and their translations are not obviously one and the same. Translation is an instrument however fallible, without which vast areas of world literature would be lost to us."(45)

Today, in the platform of twenty-first century, the interest of various scholars of literature is being generated towards comparative studies or comparative criticism with respect to CL, especially and all these practices are seen in the multilingual countries. The number of the scholars as well as their interest is ameliorating. For example, in Canada, there are two significant disciplines or trends of comparative literatures, they are: English and French. A number of significant people like Northrop Frye, Victor Graham, D.G. Jones, Ronald Sutherland and few 
other people are very often remembered in this field with respect to their noble contribution. They have contributed much in the field of comparative literature. The name of Canadian Comparative Literature Association who founded the journal - The Canadian Review of Comparative Literature published by the Department of Comparative Literature, the University of Alberta, can be taken with pride. We can mention here the name of leading Australian comparatist like David Myers and many others of Queensland University. Their job in the sphere of comparative literature is praiseworthy. Comparatists who have significant roles in the field of CL are: R.K. Dhawan R.S. Pathak, Viney Kirpal, O.M.Anujan, K.V.S. Murti, A. Ramakrishana Rao, O.P. Bhatnager, Bijay Kumar Das, Avadhesh Kumar Singh from India, David Myers from Australia and some of the critics from the Queensland University etcetera. In this field, Indian Institute of Advanced Study (IIAS), Simla, has done a great job in this field by organizing a seminar on CL, its theory and practice in June 1987. Broadening the horizon of comparative literature Bijay Kumar Das comments in his book comparative literature:

"Comparative literature transcends the narrowness, provinciality and parochialism of national and general literatures. The complacence of regional writers are shaken when the comparatists study their writings along with the writings of other writers in different other languages." (2000:04)

Max Muller has rightly told on this account that, "all higher knowledge is gained by comparison and rests on comparison." And similarly, we can quote the words of Bosanquet "comparative literature can be of immense value in freeing the mind from the shackles of provincialism and literary myopia."[17] Hence, comparative critical look will brighten the perspective of literary criticism and research as well. But still, the scope and methodology of CL has been a subject of dispute for many critics all over the world:

"It has been felt difficult to define precisely the content of comparative literature and to determine its scope. That is why, Wellek and Warren found the term 'troublesome' (Wellek \& Warren, P - 46) Lane cooper goes to the extent of saying that comparative literature is a 'bogus term and "makes neither sense nor syntax." ('Experiments in Education'

(Ithaca, Ny, 1942) (P - 75)." [18]

After knowing the perspectives of the different schools of CL all over the world, it will really be difficult to define and even to give a concrete statement about it. Today, literarute is being more and more interdisciplinary and is facing outward. Philosophy, History, Anthropology, Politics, Society, Economic condition etcetera are working as a network in which this literature falls. Hence, we cannot find a particular range and domain of a particular literature. We can perceive the direct or indirect impact of these disciplines on the piece of literature being the integral parts of the societal web. In this way, Henry Gifford says in favour of CL like this:

"The study of literature is increasingly bracketed with that of philosophy and history. It has always been difficult to set precise limits round the subject, and more and more other disciplines have thrown their shadows across literary studies. To interpret the great works of the past or for that matter of the present, the most multifarious knowledge will be required. Nearly all the subject taught in a faculty of arts will be laid at some time under contribution."(58)

A number of scholars and critics have given their significant remark regarding this CL. It is really a crucial need not only of literature but also of the hour, more particularly. Again, today we see the literature much well connected closely with the other contemporary disciplines. We can study and know the origin and development of CL in this way. According to one of the dynamic scholars, Posnett:

"Comparative literature means the general theory of literary evolution, the idea that literature passes through stages of inception, culmination and decline."(68)

Similarly, many critics have given their critical remark regarding the scopes and attitude or the perspectives of $\mathrm{CL}$ and defined the same in the following ways. According to Rene Wellek:

"Comparative literature will study all literature from an international perspective, with a consciousness of the unity of all literary creation and experience (Discriminations, p. 19)."(28) 
Here, Wellek has of course broadened the sphere and the domain of the study. Again, he says with an extension to his comment that has been quoted earlier:

Comparative literature is still a controversial discipline which has not yet been able to establish a distinct subject matter and specific methodology (Discriminations, p.1).(29)

Out of these few statements, we find the modus operandi of CL. We can truly say here that inside the territory of CL we should be broad minded and should use the entire experience collected throughout life we are related to the study. This will ensure the quality of the study and will make it stronger. We shall have to be careful enough when we are comparing the texts or the literatures. Many critics become narrow minded and strict enough with respect to the selected texts only. This is not at all a healthy practice, particularly in this forum. Rather s/he should be open and flexible to each and every text of the world related to it. Hence, the perspectives and introspections during the comparative study should neither be narrow, nor be comprehensive. With acute look, we should examine the text. And yes, here the study is always with reference to different aspects of different things. To be more particular and objective, we should ensure before going to the table of dissection of the selected texts that a comprehensive doctrines and workable methodology will facilitate the comparatists to reach their destinations. CL has not yet fully been established as a viable means of comparative study. By the way, the particular range or boundary must not be drawn there while comparing the texts. This will mar the noble beauty of the disciple. Comparison is the commonest phenomenon with human being just as an instinct. A comparatist should not be limited with the technique of comparison only but also should use the methods like description, characterization, interpretation, narration, explanation and evaluation of different works. Regarding these phenomena of CL, says Manikar:

"Comparative literature studies can include the application of the usual aesthetic values to a literature an understanding of the different literary movement and tendencies of an age, studies of themes and idea that appear in different literatures, and finally the study of genre, of structures and patterns. But perhaps the most important of all are the literary relations."[19]

CL has its right to include each and every aspect of literary criticism right from aesthetics to stylistics and other things/ elements of literature. Above all, it must be kept in mind that the literary relations must be churned out. Therefore in CL, the comparatist must keep a balance between expansion and concentration in order to produce a healthy criticism. Comparatist has got his freedom to use new tools and techniques to analyze the features of the selected works. The comparatist should have his/her insight in different disciplines such as Anthropology, Philosophy, Sociology, Psychology, History of Art and most important of all in this field - Linguistics. This will ensure the high quality comparison of the analysis. In this regard Bijay Kumar Das remarks that:

"Comparative literature analyses the similarities and dissimilarities and parallels between two literatures It further studies themes, modes, conventions and the use of folk-tales, myths in two different literatures or even more." $(01)$

Comparative literature is an open study of relationships between two or more literatures. For example - if we are selecting two literatures from two languages, it is not necessary to cite examples from the two literatures only. We can have our examples from the other peripheral literatures relating to it. Even we can cite the examples of the literatures from outside the particular nation or continent. In this way, we can have comparison between Odia literature, Hindi literature, Bengali literature, Gujarati literature, Telugu literature and other Indian literatures as well as we can have a comparison between French and Italian literature or English literature, American literature, Canadian literature, Australian literature, Indian English literature and Caribbean literature though all are written in English/any other/different languages. The study of CL encompasses all these literatures in its scope and province. In India, CL has a great prospect as it is a multi-lingual, multi-cultural, and multi religious country. A school of critics argue that Indian literature though written in many languages yet it is one having a single culture as their background. But Indian literature or culture has a kind unity amongst the diversities. Still, while ignoring the diversities we ignore the specialties 
synchronously. Every culture, every language and every sect of India has a unique specialty. It is because of the racial variety. India is really a museum of culture, race, language, tradition, customs, beliefs and many more things. Says Dr. P.K. Kar:

"The sources of diversity in India may be traced through a varity of ways, the most obvious being the ethnic origins, religions, castes, tribes, languages, social customs, cultural and subcultural beliefs, political philosophies and ideologies, geographical variations etc."(02)

"India is an ethnological museum,"(02) says Kar. From the above points we conclude that Indian culture has a certain kind of unity in diversity. But at the same time it must not be forgotten that the diversity reserves the specialty of the particular sect. They (the school of critics) argue that- only this cultural, social and religious unity among the diversity of Indian society, makes all literatures to be one i.e., Indian. In this light the words of R.K. Gupta and Priyalakshmi are worth quoting:

"If languages were in fact the decisive factor in determining the unity of a literature, then literatures written in a single language but in different nations would be regarded as one not as many literatures. But we know that this is not to be the case, English is primary vehicle of several national literatures - British, American, Canadian and Australian to name just a few and also a secondary vehicle of literary expressions in many countries of Asia, Africa and Latin America. If there can be several national literatures written in a single language, there can also be single national literature (including Indian literature) written in several languages."[20]

The arguments made by the critics are not invalid at once. Because it is not language that renders unity to literatures rather the social, cultural, historical, psychological, racial, political, economic, philosophical and religious movements and political environments play their role in this concern. Uniformity of theme (though not acutely) is one of the main factors among Indian regional literatures. Language is a cultural phenomenon conditioned by its locale and socio-cultural forces that are in operation through ages.
Every literature, every text has its own specific character of form, style, images, symbols, nuances and associations etc on the basis of its association with the specific culture, society, politics, history, geography etcetera. With respect to these things, we realize the fact that British literature is somehow and something different from other national literatures like French literature is dissimilar from English literature, from German literature and Russian literature, Italian literature, South-Asian literature, Canadian literature and Australian literature etcetera. In the very same way, if we look into the regional literature and the literatures of vernacular languages of India like Odia, Bengali, Marathi, Gujarati, Telugu, Hindi, Tamil, Assamese, Malayalam, Maithili and other languages. They are special and specific or you say unique because of the unique treatment of socio-cultural elements with the specific/respective literatures. These socio-political or the socio-cultural environment in fact decides the uniqueness of the particular literature/text. In this way the literatures gain several similarities and dissimilarities. Critics have given certain possibilities/ ways to conduct comparative evaluation of literature. "[...] Tagore and Sisir Kumar Das give emphasis on internal unity/uniformity in diversity in Indian literatures. The fundamental principle in comparative study is based upon the inter relationship between two or more than two literatures. The most essential aspect of comparative literature is the problem of method of studies. Comparative Literature can be studied fruitfully and purposefully in Indian context under the following heads, sources, themes, myths, forms, movements and trends etc." "21] While comparing the texts or the literatures we must take the movements and trends and the social setting into account of study.

"Comparative literature demands the most multifarious knowledge, worldwide farsightedness, comprehensive awareness, unbiased critical sensibility, meticulous susceptibility from the comparators to literary works or literatures so that he may collect the fact about sources, forms, themes, myths and movements and trends and vividly.",[22]

With an example of T.S. Eliot's 'The Waste Land' and Guruprasad's 'Kaalapurusha' we can have a little discussion here over this context. The Waste Land (1922) is a classic for all time till date and also will be for all time to come because it is on 
the mankind, it is for the human beings, the human race which live in this world, it is for those people who proved that they can bombard on the human heart and even can mar and paralyze several innocent generations to come. It is not only a poem of 434 lines which won the prestigious Nobel Prize in 1948 but also at the same time it is the epic of the total post-war world written in the ink which has been prepared by the blood and gene-crushed paste of human race. He became not only the best poet of twentieth century but also he was the most influencing person of the literary world. Almost every writer of each and every state and nation took Eliot as an ideal just for this noble creation: The Waste Land. He influenced numberless poets of the world of several languages. Many poems have been written for the unique creation, of course, that is The Waste Land and many lend the style and form of the poem. Now, after this poem, as Eliot did, the modern poems started being longer than they were usually before. A new tradition started thereafter. That is long-poem tradition. All the poetic caliber and credits of the poems written after this poem was not at all of the respective poets rather of T.S. Eliot for his poetic style, form and other literary uniqueness. "Eliot's poem loosely follows the legend of the Holy Grail and the Fisher King combined with vignettes of contemporary British society. Eliot employs many literary and cultural allusions from the Western canon, Buddhism and the Hindu Upanishads". [23] All most all Indian poets have been moved by T.S. Eliot for his poem. Guruprasad's Kaalapurusha is nothing but a byproduct of the irresistible influence of The Waste Land. Like Eliot, Guruprasad has his impact on the poets of his and afterward generation in Odisha and even in India. Though Sachhidananda Routray has a larger impact on the onward poetic trends of Odisha or India, still Guruprasad's poetry is of something different taste and sweetness. It will not at all be exaggerated if we say that Guruprasad's poetic style is much sweeter than Routray. For this only, many of the modern poets like to adopt the literary style of Mohanty. In this way his marvelous creation Kaalapurusha became a landmark in the literary history of Odisha. A number of postindependence poets of Odisha adopted the style of Mohanty as well as some other poets of the twenty-first century followed blindly to his poetic form, style and belief. The big thing in both of the works is of course they speak of the man only.
They never spoke of the man of England, Europe or Odisha though expressed through the local environments. They enchanted the mantras, to which the soul of mankind wanted to. That is why they are designated as classics of the world.

Myth is another significant element in different regional and national literatures. Myth, therefore easily, can create excellent area of comparative study in Indian literatures. Eventually we can quote the hopeful views of Henry Gifford: for the progress of comparative study today:

"On the one hand, the reciprocity between national literatures is constantly growing; and more and more a common fund is being built up on which writers in any language may draw. The master pieces that have hitherto stayed the possession of one people are becoming available to the world."(77-78)

In India, many universities have taken steps to enlarge the range and intensify the magnitude of CL. So far as the task of language, it may firmly be told or concluded that English, being the international language, will play more vital role in this work, i.e. the comparative analysis with regard to CL. Translation has a great function in it, i.e. before the comparative study and of course after the comparative analysis. This the platform through which a regional/local literature can be brought to the national and international platform of vision and vice versa. In this way, Indian English literature can be compared with Anglo American literature or any literature of the entire world. For example, the ancient Indian critical theories can be studied at par with western critical theories e.g. Rasa-Dhvani theory can conveniently be compared with Reader-Response theory of the West. In these ways we can have a healthy tradition cum practice of CL. This will be a perfect deconstruction of the Dhvani theory. We can look into the Reader Response Theory of Norman Holland, Stanley Fish, Wolfgang Iser, Hans-Robert Jauss, Roland Barths etcetera and Julia Kristeva's concept of text with reference to the class (Is there a text within a Class?) even here in the context of CL. How a class affects a text in different ways psychologically and in other ways, a comparatist must know. Unless $\mathrm{s} /$ he knows this $\mathrm{s} / \mathrm{he}$ cannot give the justice to the texts as well as $\mathrm{s} / \mathrm{he}$ cannot reach the tip of the objectives of CL. The characters of the texts/ the poets / writers are the elements simply to be affected by the respective 
culture and societal settings. Similarly, the readers and the critics are supposed to be affected by their contemporary environment or class whatever you say. This is the factor which helps and is responsible for the interpretation of the texts.

\section{Conclusion}

The motif, approach, aspects, skill of presentation, poetic style, meters, forms and language similarities and dissimilarities of the take/selected works or the texts/literatures all should be compared and contrasted in CL. Finding the dissimilarities implies that we are catching the specialties of the works. In each and every respect, in and every moment we compare things with one another. This is the pattern we get our own identity. One is different from other only on the basis of the dissimilarities. We may have some similarities among our culture and societal aspects but we have our own identity with us. This is the primary objective and significant-most function of CL to disseminate these things and to establish the culture universally with reference to the particular selected works/texts/literatures. Similarly, we get this conclusion that the translation tool is very important before the comparative analysis as well as after the work. We have not only to compare the texts in this forum, but also we have to do the same thing keeping the objectives of CL in mind forever. This will lead us to the successful drive of comparative study. More particularly, we have to look into the cultures beneath the texts. This is the platform where the boons and banes of these backgrounds are found and discussed to make established and to globalize the specialties of the cultures with reference to the texts. Above all, one who compares the things must have to be super specialized. Because it demands intense subject knowledge, grip to the facts of the subject, apprehension and consciousness about the subject, farsightedness, broadmindedness, comprehensive awareness, evenhanded critical sensibility, fair and open minded attitude, meticulous susceptibility from the comparators to the literary works or the selected texts. One has to grip the texts with respect to the class and other affecting factors as well as the codes of conduct of CL while analyzing the texts. After all, the result will be different every time (when research/ study is conducted by the same researcher at different times or by the different researchers at the same time) because every reader is also a character to be affected by his/her own culture, class, societal rituals, politics etcetera according to Kristeva's psychoanalytical theory of class and text with reference to the other aspects of Reader response Theory.

\section{Works cited:}

Abram, M.H. (2005). A Glossary of Literary Terms. Bangalore: Prism Books Pvt. Ltd.

Das, Bijay Kumar. (2000).Comparative Literature (ed). New Delhi: Atlanta Publishers and distributors.

Das, Bijay Kumar. (2014). Twentieth Century Literary Criticism. New Delhi: Atlanta Publishers and Distributors (P) Ltd.

Dhawan, R.K. (1987). Comparative Literature (ed). New Delhi: Behari Publication.

Gifford, Henry. (1969). Comparative Literature, New York: Humanities Press.

Guerin, Wilfred L. et. al.(1999). A Handbook of Critical Approaches to Literature. Oxford: OUP.

Kar, P.K.(2000). Indian Society. New Delhi: Kalyani Publishers.

Murfin, Ross and Supriya M. Ray. (1998). The Bedford Glossary of Critical and Literary Terms. New York: Bedford Books.

Pati. Prafulla Kumar. (2001). The Evolution of Literary Criticism. Oregon, USA: Snehalata Press.

Posnett, H.M. (1886). Comparative Literature, London.

\section{Note and References}

[1]

http://shodhganga.inflibnet.ac.in/bitstream/10603/705 1/6/06_chapter\%201.pdf

[2] R.K. Dhawan, (ed), Comparative Literature, Behari Publication, New Delhi, 1987 pp. 02.

[3]

http://shodhganga.inflibnet.ac.in/bitstream/10603/705 1/6/06_chapter\%201.pdf

${ }^{[4]}$ R.K. Dhawan, op. Cit. pp. 22.

[5]

http://shodhganga.inflibnet.ac.in/bitstream/10603/705 1/6/06_chapter\%201.pdf 
${ }^{[6]}$ R.K. Dhawan, Op. Cit. pp. 23-24.

${ }^{[7]}$ ibid- pp. 26.

[8] See, A Glossary of Literary Terms by M.H. Abrams Seventh Edition, Fifth Reprint- 2005, pp. 50-52.

[9] See The Evolution of Literary Criticism by P.K. Pati, pp.70-72.

[10]

http://shodhganga.inflibnet.ac.in/bitstream/10603/705

1/6/06_chapter\%201.pdf

[11] R.K. Dhawan, (ed), Comparative Literature, Behari Publication, New Delhi, 1987 pp. 27-28.

[12] ibid-pp. 28.

[13] T.G. Manikar, "Comparative Literature for India, Jadavpur/ Journal of Comparative Literature", 1976-77, p. 52.

[14] Bijay Kumar Das, (ed) Comparative Literature, Atlantic Publishers and distributors B2, Vishal Enclave, Opp, Rajouri Garden New Delhi-27, Year-2000 pp. 160

[15]

http://shodhganga.inflibnet.ac.in/bitstream/10603/705

1/6/06_chapter\%201.pdf

[16]

https://en.wikipedia.org/wiki/The_Waste_Land\#cite_ note-Forster-4 